\title{
Analysis of Factors Affecting Short-term Results in Elderly Patients Undergoing Elective Surgical Resection for Stage I-II Colon Cancer
}

\author{
STEFANO M.M. BASSO ${ }^{1}$, FRANCO LUMACHI ${ }^{2}$, PATRIZIO PIANON ${ }^{1}$, \\ GIOVANNI FANTI ${ }^{1}$, FEDERICA MAFFEIS ${ }^{1}$ and PAOLO UBIALI ${ }^{1}$ \\ ${ }^{1}$ Department of Surgery, General Surgery, S. Maria degli Angeli Hospital, Pordenone, Italy; \\ ${ }^{2}$ University of Padua, School of Medicine, Padua, Italy
}

\begin{abstract}
Aim: The aim of this study was to analyze the influence of comorbidities and to compare the short-term results of elective surgical resection of stage I-II colon adenocarcinoma in elderly $(\geq 65$ years) versus younger patients. Patients and Methods: Two groups of sex-matched younger and older patients were compared: Group $A: N=36$, median age 58 (range $=43-65$ ) years; and group $B: N=67$, median age 73 (range=66-86) years. Results: Overall, 71 out of 103 (68.9\%) patients had one or more comorbidities. A greater number of older patients had an American Society of Anesthesiologists (ASA) score $>2(p=0.004)$ and were on multiple medications (polypharmacy) $(p=0.016)$, but the distribution of the other parameters was similar $(p \geq 0.05)$. Intra- and postoperative complications in group $A$ vs. $B$ occurred in $25.0 \%$ vs. $26.9 \%$, and $47.2 \%$ vs. $64.2 \%$, respectively $(p \geq 0.05)$. Conclusion: Elderly patients with colon cancer scheduled to elective surgical resection should not be considered at increased risk of intra- or short-term postoperative complications with respect to younger patients. However, they require careful individual preoperative evaluation because they are usually polypharmacy users and have a higher ASA score.
\end{abstract}

This article is freely accessible online.

This work was presented, in part, at the European Society for Medical Oncology 18th World Congress on Gastrointestinal Cancer, Barcelona (Spain), 29 June-2 July 2016.

Correspondence to: Dr. Stefano Maria Massimiliano Basso, Department of Surgery, General Surgery, "S. Maria degli Angeli" Hospital, Via Montereale 24, 33170 Pordenone, Italy. Tel: +39 0434399359, Fax: +39 0434399704, email: Drsteba@tin.it, stefano.basso@aas5.sanita.fvg.it

Key Words: Elderly, colorectal cancer, comorbidities, complications, short-term results.
Colorectal cancer (CRC) is one of the most common types of cancer in the world, with more than 1.4 million new cases diagnosed yearly (1). In the USA and in the European Union, the estimated CRC incidence is approximately 41 and 44 cases per 100,000 people per year, respectively $(2,3)$. CRC primarily affects the elderly ( $\geq 65$ years), who usually have several comorbidities, potentially leading to several short- and long-term operative complications (4). Unfortunately, since CRC is quite uncommon in young people, most patients are usually considered at increased risk compared to those with other types of cancers. However, it is still unclear whether the incidence of perioperative complications differs between elderly and younger patients (5). The aim of this study was to analyze the influence of comorbidities and to compare the short-term results of curative surgery in older versus younger patients with colon adenocarcinoma, which accounts for approximately $95 \%$ of cases of colon cancer (6).

\section{Patients and Methods}

Design and study population. Our Institution's database was searched for medical records of patients with stage I-II (Dukes' A-B) colon adenocarcinoma, according to the American Cancer Society staging system (7), diagnosed and treated between 2013 and 2014. Patients with advanced (stage III-IV) cancer, other histological type of tumor, who required emergency surgery or had rectal cancer, were excluded from the study. All selected patients $(\mathrm{N}=103)$ had undergone elective surgical resection with curative intent at the same Institution. The data collected included age, gender, comorbidities, intra- and postoperative short-term (during the hospital stay) complications, operative time, intraoperative bleeding and duration of the hospital stay. There were $71(68.9 \%)$ men and $32(31.1 \%)$ women, with an overall median age of 66 years (range $=43-86$ years). The study population was divided into two groups of sex-matched patients according to their age: Group A: younger ( $\leq 65$ years), N=36 $(34.9 \%)$, median age $=58$ (range $=43-65)$ years; and group B: older ( $>65$ years), $\mathrm{N}=67(65.1 \%)$, median age $=73$ (range=66-86) years. 
Table I. Definitions and source of definition of comorbidities.

\begin{tabular}{ll}
\hline Comorbidity & Definition and source \\
\hline $\begin{array}{l}\text { American Society of Anesthesiologists } \\
\text { (ASA) score }\end{array}$ & $\begin{array}{l}\text { ASA Physical Status Classification System. Available at: } \\
\text { https://www.asahq.org/resources/clinical-information/asa-physical-status-classification-system } \\
\text { Anticoagulation therapy }\end{array}$ \\
$\begin{array}{l}\text { The use of drugs }(i . e \text {. warfarin) to reduce clot formation in the blood and to maintain the } \\
\text { International Normalized Ratio within the individual therapeutic range, usually from } 2 \text { to } 3\end{array}$ \\
Arterial hypertension, coronary artery diseases, silent ischemia, angina, heart failure, \\
arrhythmia, and peripheral arterial diseases
\end{tabular}

The conditions that patients had before surgery potentially affecting results were considered comorbidities and are reported in Table I.

Statistical analysis. The comparisons of distributions of dichotomous variables between groups were evaluated using the chi-squared $\left(\chi^{2}\right)$ test and contingency tables, or the Fisher exact probability test when expected cell frequencies were 5 or less. Assuming that the data were not normally distributed, the MannWhitney $U$-test was used to compare continuous variables. A $p$ value of less than 0.05 was considered statistically significant.

\section{Results}

The gender distribution between groups was the same $(p=0.718)$. Overall, $71(68.9 \%)$ patients had one or more comorbidities, as reported in Table II. A significantly greater $(p<0.05)$ number of older patients had an American Society of Anesthesiologists (ASA) score $>2$, and were on multiple medications (polypharmacy). A weak non-significantly increased incidence of both cardiovascular $(p=0.088)$ and chronic neurological $(p=0.058)$ disorders was observed in patients of group B, but the distribution of the other parameters was similar $(p \geq 0.05)$. Thus, the two groups were homogeneous with regard to the majority of comorbidities, excluding ASA score and polypharmacy. Overall, intraoperative complications occurred in $25.0 \%$ of group A and $26.9 \%$ of group B patients, while postoperative complications occurred in $47.2 \%$ and $64.2 \%$ patients, respectively (Figure 1). The single complication rates did not differ significantly $(p \geq 0.05)$ between younger and older patients (Table III). Both operative time $(151 \pm 35 v s .166 \pm 41 \mathrm{~min}, p=0.066)$ and postoperative hospital stay $(7.2 \pm 1.8 v s .8 .1 \pm 2.6, p=0.067)$ were shorter in group A, but the difference was not significant $(p \geq 0.05)$. Similarly, intraoperative bleeding $(81 \pm 27 v s .95 \pm 42 \mathrm{~mL}, p=0.074)$ was slightly reduced but without statistical significance.

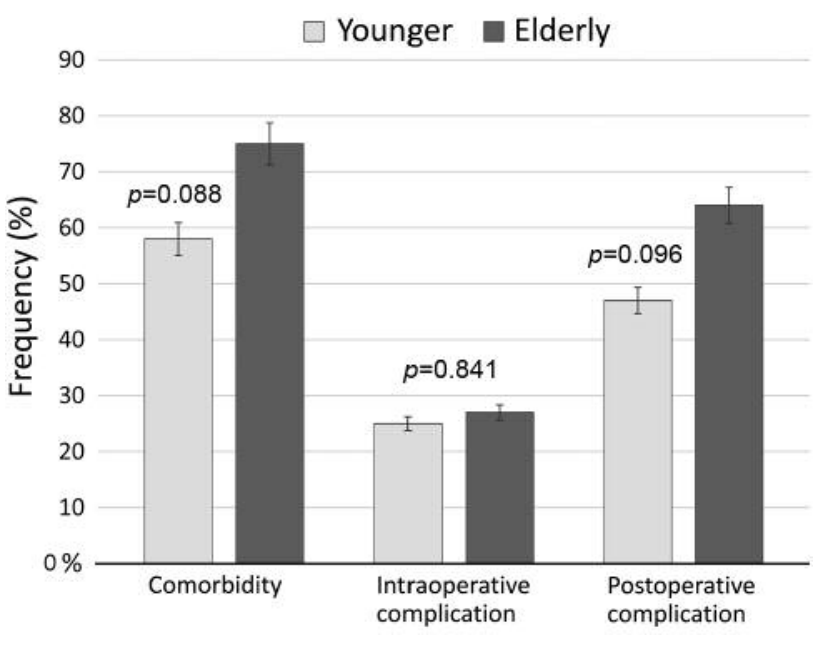

Figure 1. Rates of comorbidities and complications in the two groups of patients.

\section{Discussion}

In patients with $\mathrm{CRC}$ undergoing elective surgery, the rate of postoperative complications ranges widely, approximately from $33 \%$ to $57 \%$ (11-14). According to a cumulative review, the most frequent complications were prolonged ileus, pneumonia, and urinary tract infections, while the main risk factors were age, male gender, ASA score, and malnutrition (15). In patients taking anticoagulants, including vitamin $\mathrm{K}$ antagonists, several concomitant factors may lead to an increased risk for major hemorrhage (16). More recent studies report other predictors, including cancer stage, operative time, and blood loss $(13,14)$. The presence of 
Table II. Comorbidity rates in the overall study population and in the two groups of patients.

\begin{tabular}{|c|c|c|c|c|c|}
\hline Comorbidity & Overall & Group A ( $\leq 65$ years) & Group B ( $>65$ years) & $\mathrm{RR}(95 \% \mathrm{CI})$ & $p$-Value \\
\hline Anticoagulation therapy & $26.2 \%$ & $16.7 \%$ & $31.3 \%$ & $1.21(0.97-1.51)$ & 0.106 \\
\hline ASA score $>2$ & $34.9 \%$ & $20.0 \%$ & $44.8 \%$ & $1.51(1.16-1.96)$ & 0.004 \\
\hline $\mathrm{BMI}>25 \mathrm{~kg} / \mathrm{cm}^{2}$ & $14.6 \%$ & $16.7 \%$ & $13.4 \%$ & $0.96(0.81-1.14)$ & 0.654 \\
\hline Body weight loss $>10 \%$ & $12.6 \%$ & $11.1 \%$ & $13.4 \%$ & $1.03(0.88-1.19)$ & 0.770 \\
\hline Cardiovascular disorders & $33.0 \%$ & $22.2 \%$ & $38.8 \%$ & $1.27(0.98-1.65)$ & 0.088 \\
\hline Type 1 or 2 diabetes mellitus & $16.5 \%$ & $13.9 \%$ & $17.9 \%$ & $1.05(0.88-1.25)$ & 0.603 \\
\hline Liver/renal failure & $15.5 \%$ & $13.9 \%$ & $16.4 \%$ & $1.03(0.87-1.22)$ & 0.740 \\
\hline Chronic neurological disorders & $14.6 \%$ & $5.6 \%$ & $19.4 \%$ & $1.18(1.02-1.35)$ & 0.058 \\
\hline Chronic obstructive pulmonary diseases & $15.5 \%$ & $11.1 \%$ & $17.9 \%$ & $1.08(0.92-1.27)$ & 0.362 \\
\hline Smokers & $18.4 \%$ & $22.2 \%$ & $16.4 \%$ & $0.93(0.76-1.14)$ & 0.473 \\
\hline Polypharmacy & $49.5 \%$ & $33.3 \%$ & $58.2 \%$ & $1.59(1.11-2.30)$ & 0.016 \\
\hline None & $31.1 \%$ & $41.7 \%$ & $25.4 \%$ & $0.78(0.57-1.06)$ & 0.088 \\
\hline
\end{tabular}

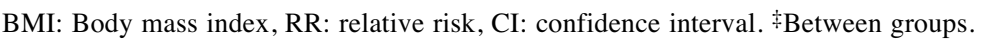

Table III. Intra- and postoperative short-term complications (\%) in the overall population and in the two groups of patients.

\begin{tabular}{|c|c|c|c|c|c|}
\hline Complication & Overall & Group A ( $\leq 65$ years) & Group B (>65 years) & $\mathrm{RR}(95 \% \mathrm{CI})$ & $p$-Value ${ }^{\ddagger}$ \\
\hline \multicolumn{6}{|l|}{ Intraoperative } \\
\hline Bowel injury & $2.9 \%$ & $2.8 \%$ & $3.0 \%$ & $1.00(0.93-1.07)$ & 0.720 \\
\hline Splenic injury & $4.9 \%$ & $5.6 \%$ & $4.5 \%$ & $0.99(0.90-1.07)$ & 0.598 \\
\hline Ureter/bladder injury & $1.9 \%$ & $2.8 \%$ & $1.5 \%$ & $0.98(0.93-1.05)$ & 0.579 \\
\hline Serious bleeding* & $2.9 \%$ & $5.6 \%$ & $3.0 \%$ & $1.00(0.93-1.07)$ & 0.720 \\
\hline Other complication & $6.8 \%$ & $5.6 \%$ & $7.5 \%$ & $1.02(0.92-1.13)$ & 0.532 \\
\hline None & $73.8 \%$ & $75.0 \%$ & $73.1 \%$ & $0.93(0.47-1.85)$ & 0.841 \\
\hline \multicolumn{6}{|l|}{ Postoperative } \\
\hline Anastomotic leak & $9.7 \%$ & $8.3 \%$ & $10.4 \%$ & $1.02(0.90-1.16)$ & 0.513 \\
\hline Pneumonia/pleural effusion & $27.2 \%$ & $11.1 \%$ & $20.9 \%$ & $1.12(0.95-1.33)$ & 0.213 \\
\hline Sub-ileus & $7.8 \%$ & $5.6 \%$ & $8.9 \%$ & $1.04(0.94-1.16)$ & 0.423 \\
\hline Sepsis & $2.9 \%$ & $2.8 \%$ & $3.0 \%$ & $1.00(0.93-1.07)$ & 0.720 \\
\hline Surgical site infection & $9.7 \%$ & $11.1 \%$ & $11.9 \%$ & $1.01(0.87-1.17)$ & 0.587 \\
\hline Urinary tract infection & 18.4 & 13.9 & 20.9 & $1.09(0.91-1.30)$ & 0.383 \\
\hline Other complication & 12.6 & 8.3 & 14.9 & $1.08(0.94-1.24)$ & 0.376 \\
\hline Reoperation & 3.9 & 2.8 & 4.5 & $1.02(0.94-1.10)$ & 0.563 \\
\hline None & 41.7 & 52.8 & 35.8 & $0.74(0.50-1.09)$ & 0.096 \\
\hline
\end{tabular}

RR: Relative risk, CI: confidence interval. *Requiring intraoperative blood transfusion. $\doteqdot$ Between groups.

chronic pulmonary diseases is a risk factor for intraoperative complication but does not affect postoperative results, although usually prolonging hospital stay (17). In this study, the main intraoperative complication occurring in patients with rectal cancer was spleen injury. In elderly patients with CRC, a lack of cardiovascular comorbidities does not reduce the occurrence of postoperative complications, but a higher ASA grade significantly affects their recovery rate and mortality $(18,19)$. Older patients may have more infective complications with respect to younger ones, but laparoscopic surgery significantly reduces the morbidity rate and amount of blood loss $(13,14,20)$.

\section{Conclusion}

We conclude that older patients ( $>65$ years) with colon cancer scheduled for elective surgical resection should not be considered at increased risk of intra- or short-term postoperative complications with respect to younger patients. However, the elderly require careful individual preoperative 
evaluation when they have more than one comorbidity because they are usually users of multiple medications, and may more frequently have a higher ASA score.

\section{References}

1 World Research Cancer Fund International. Colorectal cancer statistics. Available at: http://www.wcrf.org/int/cancer-factsfigures/data-specific-cancers/colorectal-cancer-statistics

2 National Cancer Institute. Surveillance, Epidemiology, and End Results Program (SEER). Cancer Stat Facts: Colon and Rectum Cancer. Available at: https://seer.cancer.gov/statfacts/html/ colorect.html

3 Ferlay J, Steliarova-Foucher E, Lortet-Tieulent J, Rosso S, Coebergh JW, Comber H, Forman D and Bray F: Cancer incidence and mortality patterns in Europe: estimates for 40 countries in 2012. Eur J Cancer 49: 1374-1403, 2013.

4 Kvasnovsky CL, Adams K, Sideris M, Laycock J, Haji AK, Haq A, Nunoo-Mensah J and Papagrigoriadis S: Elderly patients have more infectious complications following laparoscopic colorectal cancer surgery. Colorectal Dis 18: 94-100, 2016.

5 Deiner S, Westlake B and Dutton RP: Patterns of surgical care and complications in the elderly. J Am Geriatr Soc 62: 829-835, 2014.

6 Fleming M, Ravula S, Tatishchev SF and Wangcorresponding HL: Colorectal carcinoma: Pathologic aspects. J Gastrointest Oncol 3: 153-173, 2012.

7 American Cancer Society. Colorectal cancer stages. Available at: https://www.cancer.org/cancer/colon-rectal-cancer/detectiondiagnosis-staging/staged.html

8 American Diabetes Association: Diagnosis and classification of diabetes mellitus. Diabetes Care 37(Suppl 1): S81-90, 2014.

9 Albers I, Hartmann H, Bircher J and Creutzfeldt W: Superiority of the Child-Pugh classification to quantitative liver function tests for assessing prognosis of liver cirrhosis. Scand $\mathrm{J}$ Gastroenterol 24: 269-276, 1989.

10 Maher RL, Hanlon J and Hajjar ER: Clinical consequences of polypharmacy in elderly. Expert Opin Drug Saf 13: 57-65, 2014.

11 Tominaga T, Takeshita H, Takagi K, Kunizaki M, To K, Abo T, Hidaka S, Nanashima A, Nagayasu T and Sawai T: E-PASS score as a useful predictor of postoperative complications and mortality after colorectal surgery in elderly patients. Int $\mathrm{J}$ Colorectal Dis 31: 217-225, 2016.
12 Mokutani Y, Mizushima T, Yamasaki M, Rakugi H, Doki Y and Mori M: Prediction of postoperative complications following elective surgery in elderly patients with colorectal cancer using the Comprehensive Geriatric Assessment. Dig Surg 33: 470-477, 2016.

13 Kvasnovsky CL, Adams K, Sideris M, Laycock J, Haji AK, Haq A, Nunoo-Mensah J and Papagrigoriadis S: Elderly patients have more infectious complications following laparoscopic colorectal cancer surgery. Colorectal Dis 18: 94-100, 2016.

14 Tei M, Ikeda M, Haraguchi N, Takemasa I, Mizushima T, Ishii $\mathrm{H}$, Yamamoto $\mathrm{H}$, Sekimoto $\mathrm{M}$, Doki $\mathrm{Y}$ and Mori $\mathrm{M}$ : Postoperative complications in elderly patients with colorectal cancer: comparison of open and laparoscopic surgical procedures. Surg Laparosc Endosc Percutan Tech 19: 488-492, 2009.

15 Kirchhoff P, Clavien PA and Hahnloser D: Complications in colorectal surgery: risk factors and preventive strategies. Patient Saf Surg 4: 5, 2010.

16 Shoeb M and Fang MC: Assessing bleeding risk in patients taking anticoagulants. J Thromb Thrombolysis 35: 312-319, 2013.

17 Riss S, Mittlböck M, Riss K, Chitsabesan P and Stift A: Intraoperative complications have a negative impact on postoperative outcomes after rectal cancer surgery. Int J Surg 12: 833-836, 2014.

18 Arenal-Vera JJ, Tinoco-Carrasco C, del-Villar-Negro A, LabargaRodríguez F, Delgado-Mucientes A and Cítores MA: Colorectal cancer in the elderly: characteristics and short term results. Rev Esp Enferm Dig 103: 408-415, 2011.

19 An Q, Yu T, Cao X, Yang H, Zhao G, Wu G, Jia W and Xiao G: Comparative analysis of postoperative complications on elderly colorectal cancer patients over 65 years with and without comorbid cardiovascular diseases. Zhonghua Wei Chang Wai Ke Za Zhi 19: 1035-1039, 2016.

20 Fujii S, Ishibe A, Ota M, Yamagishi S, Watanabe K, Watanabe J, Kanazawa A, Ichikawa Y, Oba M, Morita S, Hashiguchi Y, Kunisaki C and Endo I: Short-term results of a randomized study between laparoscopic and open surgery in elderly colorectal cancer patients. Surg Endosc 28: 466-476, 2014.

Received January 23, 2017

Revised March 1, 2017

Accepted March 9, 2017 